\title{
Sudden onset flank pain: a case report of retroperitoneal hemorrhage secondary to a ruptured adrenal hemangioma
}

This article was published in the following Dove Press journal: Journal of Pain Research

\author{
Xufeng Peng ${ }^{1,2}$ \\ Wenqiang Luo',2 \\ Xinru Zhang ${ }^{1,2}$ \\ Weidong Zhu', \\ 'Department of Urology, Shanghai \\ Jiao Tong University Affiliated \\ Sixth People's Hospital, Shanghai, \\ China; ${ }^{2}$ Shanghai Eastern Urological \\ Reconstruction and Repair Institute, \\ Shanghai, China
}

\begin{abstract}
Background: Acute abdominal pain is a common complaint of patients presenting at the emergency department (ED). It can be caused by a broad spectrum of diseases. Providing care for patients with acute abdominal pain requires familiarity with the epidemiology, prevalence, and presentation of abdominal pathology, as well as a working knowledge of the differential diagnoses. Case report: In this article, we discuss a case of spontaneous rupture of adrenal hemangioma with large retroperitoneal hemorrhage in a 31-year-old female.

Discussion: Emergency physicians regularly encounter uncommon causes of abdominal pain. Spontaneous rupture of adrenal hemangioma is an extremely rare cause of abdominal pain, but proper understanding of the disease process will aid clinicians to make a final diagnosis and ensure appropriate treatment. In this study, presentations and risk factors for spontaneous, atraumatic rupture of adrenal hemangioma as well as ED management and definitive treatment options are discussed.
\end{abstract}

Keywords: retroperitoneal hemorrhage, flank pain, adrenal hemangioma, spontaneous rupture

\section{Introduction}

Abdominal pain is cited as the most common reason for visiting the emergency department (ED) in the 18- to 64-year age group and is the third most common reason in the population older than 65 years. ${ }^{1}$ A patient's age, sex, risk factors, and comorbid conditions help guide differential diagnoses, risk stratification, and management. However, atypical presentations of serious pathology may share many symptoms with more benign causes of abdominal pain (Table 1). ${ }^{2,3}$ In this article, we discuss a case of a 31-year-old female presenting with sudden onset of right flank pain and hypotension $(85 / 50 \mathrm{mmHg})$, which was initially suspected as abdominal aortic aneurysm rupture but was confirmed to be a case of spontaneous rupture of adrenal hemangioma with large retroperitoneal hemorrhage. Appropriate treatment options and ED management vary based on patient risk factors, stability, and etiology of hemorrhage, which are discussed in this report.

\section{Ethics approval and consent to participate}

Written informed consent was obtained from the patient for the publication of this case report and the related images.

\section{Case presentation}

A 31-year-old female was referred to the ED with spontaneous onset pain in the right upper quadrant and flank region accompanied by nausea and flatulence. Initial vitals 
Table I Percentage of the most frequent causes of abdominal pain'

\begin{tabular}{lll}
\hline Diagnosis & $\begin{array}{l}<\mathbf{5 0} \text { years } \\
\text { old }\end{array}$ & $\begin{array}{l}>\mathbf{5 0} \text { years } \\
\text { old }\end{array}$ \\
\hline Biliary disease & 6 & 21 \\
Nonspecific abdominal pain (UDP) & 40 & 16 \\
Appendicitis & 32 & 15 \\
Bowel obstruction & 2 & 12 \\
Pancreatitis & 2 & 7 \\
Perforation & & 7 \\
Diverticulitis & $<0.1$ & 6 \\
Cancer & $<0.1$ & 4 \\
Hernia & $<0.1$ & 3 \\
Vascular & $<0.1$ & 2 \\
Gynecological & 4 & $<0.1$ \\
Urological & 12 & 8
\end{tabular}

Abbreviation: UDP, undifferentiated abdominal pain.

were apyretic, respiratory rate $28 / \mathrm{min}$, heart rate 118 beats/ min, blood pressure $85 / 50 \mathrm{mmHg}$, with normal oxygen saturation. On physical examination, the patient had significant pain in the epigastric and right flank region with involuntary guarding, but signs of peritoneal irritation or a palpable intraabdominal mass were absent. There was no evidence of acute cholecystitis, appendicitis, or peritonitis. The patient had no history of surgery, trauma, calculus, and drug abuse. Her family and social histories were unremarkable.

Laboratory investigation showed a white blood cell count of $11.3 \mathrm{~K} / \mathrm{cmm}$, hemoglobin of $48 \mathrm{~g} / \mathrm{dL}$, hematocrit of $30.7 \%$, and serum creatinine of $2.4 \mathrm{mg} / \mathrm{dL}$. Tumor markers, including alpha-fetoprotein, carcinoembryonic antigen, and carbohydrate antigen (CA 199 and CA 125), were within normal limits. Also, no abnormal data in the blood hormonal sampling, including adrenocorticotropic hormone, cortisol, aldosterone, and epinephrine, were observed. Bedside ultrasound of the abdomen revealed an irregular and heterogeneous mass in the retroperitoneal space with an obvious fluid collection in the right subhepatic space. Hemoglobin on repeat cell count was $39 \mathrm{~g} / \mathrm{dL}$. After a rapid intravenous infusion of $500 \mathrm{ml}$ of Ringer's lactate solution and $500 \mathrm{ml}$ of $10 \%$ hydroxyethyl starch, urgent non-contrast-enhanced computed tomography (CT) of the abdomen showed a $7 \times 8$ $\mathrm{cm}$ well-contained, right-sided retroperitoneal hemorrhage between the liver and right kidney (Figure 1).

An urgent laparotomy was performed, revealing a massive right-sided retroperitoneal hematoma with a small amount of intraperitoneal blood. The ascending colon was mobilized to give a more complete view of this large mass and hematoma situated between the liver and right kidney. The right adrenal gland was closely adherent and was excised along with the mass. The cut surface of the mass showed some areas of necrosis. Histological examination confirmed the features of cavernous hemangioma. Microscopically, histology showed degenerative changes in vessel walls, some of which were obliterated. The blood-filled lacunae were lined by benign endothelial cells. The periphery represented a normal adjacent adrenal gland (Figure 2). There were no signs of malignancy. The patient did well postoperatively and was

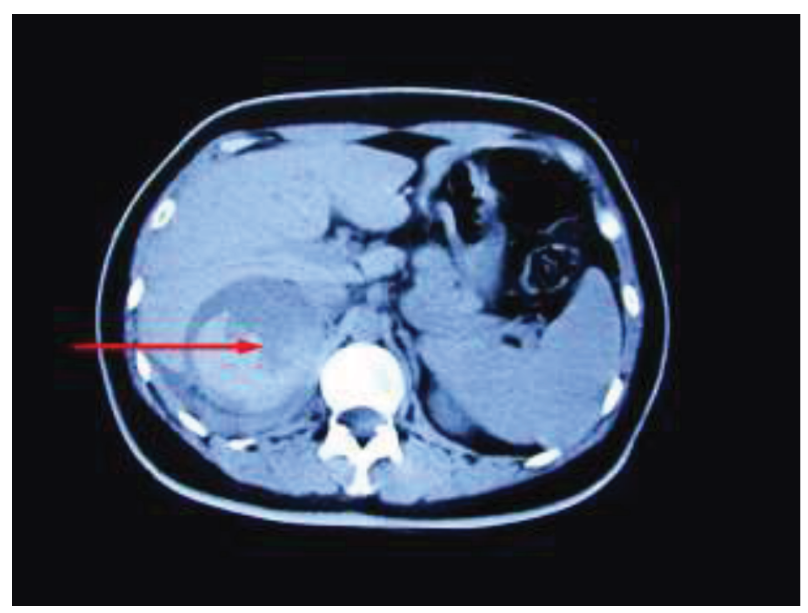

Figure I Abdominal computed tomographic scan revealing a large, right-sided retroperitoneal mass (red arrow).

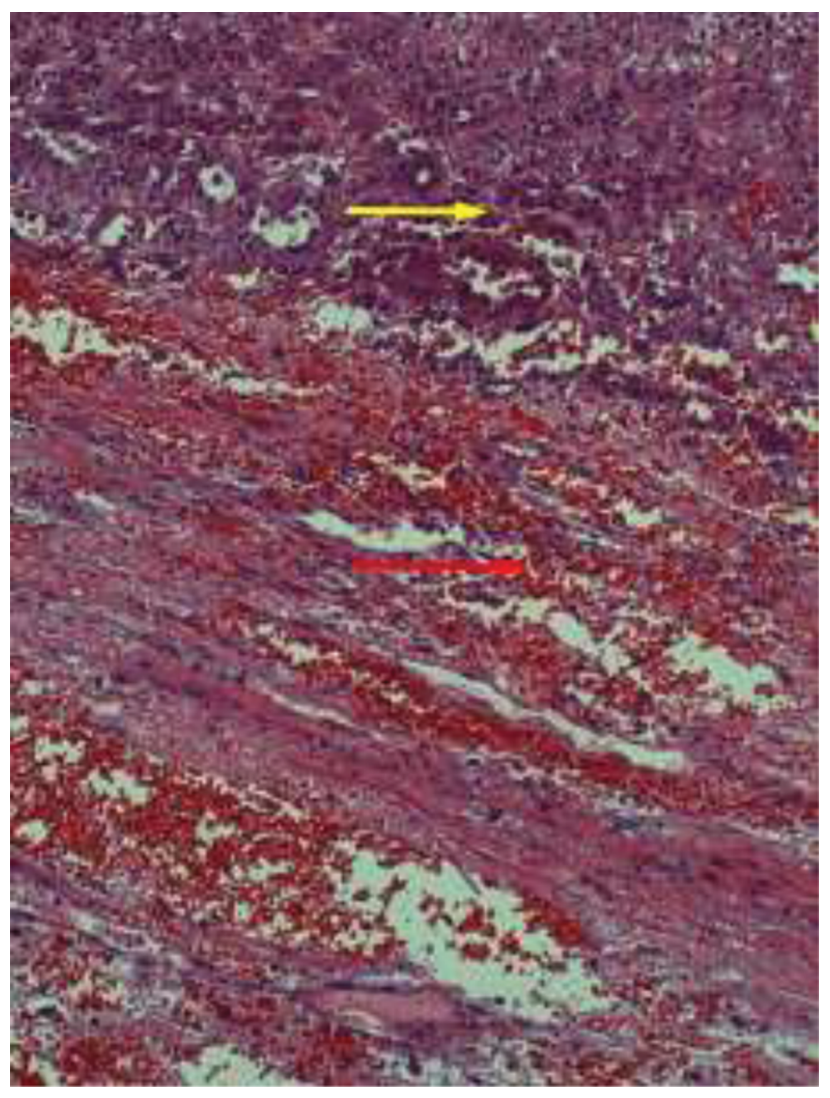

Figure 2 Hematoxylin and eosin staining showing blood filled dilated vascular spaces with single lining of endothelial cells (red arrow) and adjacent normal adrenal tissues (yellow arrow). Original magnification: $\times 200$. 
discharged after 7 days. Surgical resection was curative, with no recurrence at the 1-year follow-up.

\section{Discussion}

In atraumatic conditions, the most common cause of a severe retroperitoneal hemorrhage in adults is rupture of the abdominal aorta or other retroperitoneal large vessel aneurysm. ${ }^{4}$ However, several other conditions can mimic this, including coagulopathy, renal carcinoma, renal calculi, renal cyst, pheochromocytoma, cortical adenoma, adrenocortical carcinoma, adrenal metastasis, adrenal hemangioma, and pancreatic pathology. ${ }^{5-9}$ To date, about 90 cases of adrenal hemangiomas have been documented in literature. ${ }^{10}$ Most of the described cases were asymptomatic and incidentally discovered during imaging studies performed for an unrelated reason (ie, incidentaloma). Unusual bleeding from a spontaneously ruptured adrenal hemangioma, presenting with hematomas of the scrotum and penis but no signs of massive hemorrhage, was reported by Fernandez Ruiz et al. ${ }^{11}$ Hemorrhages into a large adrenal hemangioma without tumor rupture were presented in two other cases. ${ }^{12,13}$ In 2008 , Paluszkiewicz et al reported the first case of a spontaneously ruptured adrenal hemangioma, which cased life-threatening retroperitoneal hemorrhage. ${ }^{14}$ Presented in this case report is the second reported incidence of retroperitoneal hemorrhage caused by adrenal hemangioma.

Adrenal hemangiomas are benign neoplasms arising from endothelial cells that line blood vessels. ${ }^{15}$ The causes of these tumors are unknown; probably many of these are congenital with the involvement of hereditary factors and ectasia of blood vessels. ${ }^{16}$ Adrenal hemangiomas are mostly cavernous, unilateral lesions of the adrenal glands; bilateral involvement has been reported twice, and appears between the ages 50 and 70 years, with a $2: 1$ female-to-male ratio. ${ }^{17}$ Patients usually have no signs and symptoms and have been noticed only when they have large palpable masses or hypovolemic shock caused by spontaneous rupture. Instances of adrenal hyperfunction are almost nonexistent, with only three reported cases of hormone-secreting adrenal hemangiomas. ${ }^{18-20}$

Early identification is crucial in patients with spontaneous rupture of adrenal hemangioma. Valid diagnostic methods in such cases are subtracted arteriography, CT angiography, and T2-weighted spinecho magnetic resonance imaging. Pathognomonic symptoms seen with adrenal hemangioma involve unilateral adrenal enlargement, cystic degeneration, and calcification. ${ }^{21}$

Surgical excision remains mandatory for large adrenal masses exceeding $3.5 \mathrm{~cm}$ in size due to the impossibility of excluding malignancy. ${ }^{10}$ Other indications for surgery include mass-effect-type symptoms from neighboring organs and complications such as hemorrhage. ${ }^{22}$ Adrenal hemangioma can be totally cured by surgical procedure. No evidence of tumor recurrence was found. There were no reports on mortality associated with this entity. Presently, several open techniques have been described, including transabdominal, flank, and posterior approaches. Although laparoscopic adrenalectomy is standard procedure for small adrenal masses, it is still controversial for giant adrenal masses. ${ }^{15} \mathrm{In}$ this patient, the adrenal hemangioma was excised with open transabdominal surgery due to the bleeding and size of the mass. In our opinion, the treatment of spontaneous rupture of adrenal hemangioma with large retroperitoneal hemorrhage required rapid surgical hemostasis and concurrent correction of hypovolemia and blood constitution. It seems that the urgent open surgery is a reasonable option in treating the case of spontaneous rupture of adrenal hemangioma.

In summary, retroperitoneal hemorrhage is an unusual complication of spontaneous rupture of adrenal hemangioma. Although rare, this case demonstrates a serious condition, which must be rapidly differentiated from more common causes of abdominal and flank pain, as knowledge of retroperitoneal hemorrhage secondary to a ruptured adrenal hemangioma and timely disposition to proper specialty resources may improve patient outcomes and prove invaluable to the emergency physician practicing in the community setting.

\section{Author contributions}

All authors contributed toward data analysis, drafting and critically revising the paper, gave final approval of the version to be published, and agree to be accountable for all aspects of the work.

\section{Disclosure}

The authors report no conflicts of interest in this work.

\section{References}

1. National Center for Health Statistics (US). Health, United States, 2012. With Special Feature on Emergency Care. Hyattsville, MD: National Center for Health Statistics (US); 2013.

2. Brown HF, Kelso L. Abdominal pain: an approach to a challenging diagnosis. AACN Adv Crit Care. 2014;25(3):266-278.

3. Grubb SM, Stuart JI, Harper HM. Sudden onset flank pain: spontaneous renal rupture. Am J Emerg Med. 2017;35(11):1787e1781-1787e1783

4. Sunga KL, Bellolio MF, Gilmore RM, Cabrera D. Spontaneous retroperitoneal hematoma: etiology, characteristics, management, and outcome J Emerg Med. 2012;43(2):e157-e161.

5. Katabathina VS, Katre R, Prasad SR, Surabhi VR, Shanbhogue AK, Sunnapwar A. Wunderlich syndrome: cross-sectional imaging review. J Comput Assist Tomogr. 2011;35(4):425-433.

6. Sotosek S, Markic D, Spanjol J, Krpina K, Knezevic S, Maricic A. Bilateral wunderlich syndrome caused by spontaneous rupture of renal angiomyolipomas. Case Rep Urol. 2015;2015:316956. 
7. Orikasa K, Namima T, Ohnuma T, Munakata M, Kimura N, Arai Y. Spontaneous rupture of adrenal pheochromocytoma with capsular invasion. Int J Urol. 2004;11(11):1013-1015.

8. Nakajo M, Onohara S, Shinmura K, Fujiyoshi F, Nakajo M. Embolization for spontaneous retroperitoneal hemorrhage from adrenal myelolipoma. Radiat Med. 2003;21(5):214-219.

9. Kawashima A, Sandler CM, Ernst RD, et al. Imaging of nontraumatic hemorrhage of the adrenal gland. Radiographics. 1999;19(4):949-963.

10. Agrusa A, Romano G, Salamone G, et al. Large cavernous hemangioma of the adrenal gland: Laparoscopic treatment. Report of a case. Int J Surg Case Rep. 2015;16:150-153.

11. Fernandez Ruiz M, Diez Ferez P, Vizcaino Lopez A, et al. [Adrenal hemangioma: unusual cause of retroperitoneal hemorrhage]. Arch Esp Urol. 1995;48(1):82-85. Spanish.

12. Forbes TL. Retroperitoneal hemorrhage secondary to a ruptured cavernous hemangioma. Can J Surg. 2005;48(1):78-79.

13. Gonzalez Munoz GF, Martinez Alarcon M, Fernandez Garcia ML. [Adrenal hemangioma of atypical presentation. Bibliographical review]. Arch Esp Urol. 1998;51(2):191-194.

14. Paluszkiewicz P, Ambroziak I, Holynska-Dabrowska K, SiezieniewskaSkowronska Z, Paluszkiewicz A. Spontaneous rupture of adrenal haemangioma mimicking abdominal aortic aneurysm rupture. Arch Med Sci. 2010;6(1):122-125.
15. Tarchouli M, Boudhas A, Ratbi MB, et al. Giant adrenal hemangioma: Unusual cause of huge abdominal mass. Can Urol Assoc J. 2015;9(11-12):E834-E836.

16. Noh JJ, Choi SH, Hwang HK, Kang CM, Lee WJ. Adrenal cavernous hemangioma: a case report with review of the literature. JOP. 2014;15(3): 254-257.

17. Sabanegh E Jr, Harris MJ, Grider D. Cavernous adrenal hemangioma. Urology. 1993;42(3):327-330.

18. Oh BR, Jeong YY, Ryu SB, Park YI, Kang HK. A case of adrenal cavernous hemangioma. Int J Urol. 1997;4(6):608-610.

19. Ng AC, Loh HL, Shum CF, Yip SK. A case of adrenal cavernous hemangioma presenting with progressive enlargement and apparent hormonal hypersecretion. Endocr Pract. 2008;14(1):104-108.

20. Stumvoll M, Fritsche A, Wehrmann M, Dammann F, Becker HD, Eggstein M. A functioning adrenocortical hemangioma. J Urol. 1996;155(2):638.

21. Boraschi P, Campatelli A, Di Vito A, Perri G. Hemorrhage in cavernous hemangioma of the adrenal gland: US, CT and MRI appearances with pathologic correlation. Eur J Radiol. 1995;21(1):41-43.

22. Alhajri K, Alhasan I, Alzerwi N, Abudaff N. Adrenal haemangioma. BMJ Case Rep. 2011;2011:bcr1220103604.
Journal of Pain Research

\section{Publish your work in this journal}

The Journal of Pain Research is an international, peer reviewed, open access, online journal that welcomes laboratory and clinical findings in the fields of pain research and the prevention and management of pain. Original research, reviews, symposium reports, hypothesis formation and commentaries are all considered for publication.

\section{Dovepress}

The manuscript management system is completely online and includes a very quick and fair peer-review system, which is all easy to use. Visit http://www.dovepress.com/testimonials.php to read real quotes from published authors. 